\title{
Association of psychological morbidity with socio-demographic characteristics among elderly: A cross-sectional study from Eastern India
}

Pratyay Pratim Datta, Nilanjan Gangopadhyay', Bhaswati Sengupta ${ }^{2}$

Department of Pharmacology, $\mathrm{Hi}$-Tech Medical College and Hospital, Bhubaneswar, Odisha, ${ }^{1}$ Department of Public Health Administration, West Bengal, Public Health cum Administrative Service, West Bengal, ${ }^{2}$ All India Institute of Hygiene and Public Health, Kolkata, India

\section{Address for the Correspondence:}

Dr. Pratyay Pratim Datta, Department of Pharmacology, $\mathrm{Hi}$-Tech Medical College and Hospital, Health Park, Pandara,

Rasulgarh, Bhubaneswar,

Odisha - 751 025, India. E-mail: pratyaypratimdatta@ gmail.com

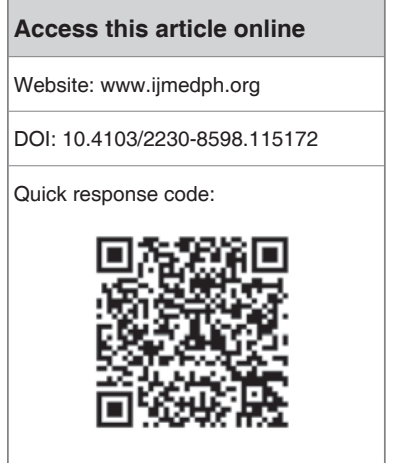

Background: The psychological morbidity of the geriatric people is very common. There are different socio-demographic factors affecting the psychological health of elderly, which have not been studied in detail in India. Objective: The present study was framed to find out the association of different socio-demographic factors with the psychological morbidity of the elderly. Materials and Methods: It was a community-based cross-sectional study conducted in Municipal area of Tarakeswar, Hooghly District, West Bengal, India among the geriatric people using a pre-designed, pre-tested, semi-structured schedule to collect the socio-demographic data. General Health Questionnaire-28 was used to collect data regarding psychological morbidity. Statistical analysis was done using SPSS version 16.0. Results: It was revealed that only $29.4 \%$ of the respondents scored within normal range. Multiple linear regression taking total as well as domain-wise scoring as dependent variable revealed that increasing age, female sex, illiteracy, financial dependency on other family members, not living with spouse, and poor socio-economic status are significantly associated with psychological morbidity. Conclusion: Overall mental health condition of geriatric people is not good. Proper rehabilitation measures have to be taken by family members, society, and government like engaging them in light activities of their interest, old age pension scheme or forming self-help group among elderly, which would result in making them happy.

Key words: Geriatric, GHQ-28, psychological morbidity

\section{INTRODUCTION}

The term geriatric indicates elderly population. In India, geriatric is defined as population aged 60 years and above. ${ }^{[1]}$ The regeneration capacity of cells and other processes due to growth and maturation is lost over time, ultimately leading to incompatibility with life. ${ }^{[2]}$ There is continuous increase in the life expectancy throughout the world. But, the rate of increase in the average life span of people in developing countries is dramatic. ${ }^{[3]}$ This demographic transition has been accompanied by changes in society and economy. Due to shortage of space in metropolitan area with higher rents, migrants often prefer to leave their parents in the native place. This group of people often feels neglected by their family members. Often, the elderly people are not able to cope up with the rapidly changing world. The prevalence of psychological morbidity and even psychiatric diseases are often very high in this age groups ${ }^{[4]}$ compared to others. A large chunk of geriatric population suffers from major depression. Other psychological problems like somatic symptoms are also high among them. With an increase in age, the duration of sleep usually gradually declines. So, prevalence of insomnia is highest in elderly people. All these different types of psychological problems have strong relations with socio-demographic factors.

In this background, the present study was framed to find out the psychological morbidities among geriatric people in an urban community of Eastern India and to find out the association of psychological morbidities with different socio-demographic factors. 


\section{MATERIALS AND METHODS}

\section{Study site and population}

This was a community-based cross-sectional study. The study was conducted at municipal area of Tarakeswar town, Hooghly district, West Bengal, India. The town covering $3.88 \mathrm{sq} \mathrm{km}$ area had 2258 geriatric people in the study period. The town is outside the metropolitan area of Kolkata, and a large proportion of residents of this area commute to Kolkata on daily basis for livelihood. So, the socio-cultural background of this area has a mixture of metropolitan culture and non-metropolitan culture.

\section{Sample size and study design}

The study period was from June 2009 to March 2010. Line listing of total 2258 geriatric people was obtained from municipal authority of Tarakeswar. Out of 15 wards in Tarakeswar municipality area, three were chosen by simple random sampling technique. All the elderly people in these three wards were planned to be approached to participate in the present study. The elderly people who were not present in home even after three repeated visits were excluded from the study. People, who did not want to take part in the study, were excluded. Informed consent was taken from others who took part in the study. Finally, 402 geriatric people participated in the present study.

\section{Study parameters and study tools}

Data were collected using pre-designed, pre-tested, semi-structured schedule. Data regarding age, sex, literacy, financial dependency, marital status, and per capita monthly income were collected by interviewing the study subjects using the schedule. Data regarding psychological morbidity was collected using General Health Questionnaire-28 (GHQ-28) developed by David Goldberg. The questionnaire has 28 individual questions each having four options. GHQ-28 covers four domains of psychological morbidity-there are seven questions for each domain. The domains are somatic symptoms, anxiety-insomnia, social dysfunction, and severe depression. The Bengali version developed by Banerjee was used in the present study. The scoring system used in this study was GHQ scoring. This indicates zero score if the respondent answers between either first or second option. On the other hand, he/she will get a score of one if the answer is either third or fourth option. So, the total possible score ranges from zero to 28 . Maximum possible score of each domain is seven. If the total score of a person is 10 or more, then he/she can be considered as a psychological case. If the score ranges between $5-9$, then he/she is considered to be psychological caseness, which indicates that there is $50 \%$ chance of suffering from psychological morbidity.

\section{Statistical analysis}

After collection of data, it was double-entered in Microsoft Excel sheet and validated. A clean Database was generated and copied into SPSS sheet (version 16.0). Then, analysis of the data was done in SPSS (version 16.0). Initially, frequency distribution of different socio-demographic parameters and proportion of caseness, case, and normal people were analyzed. After this, Chi-square test of statistical significance was done to find the association of psychological morbidities with different socio-demographic parameters. After this, multiple linear regression was done to properly find out the association of different socio-demographic parameters with total GHQ score and different domain-wise score.

\section{RESULTS}

Out of 402 respondents who took part in the present study, $176(43.8 \%)$ were male and rest $(56.2 \%)$ were female. Most of the study population was under 70 years of age $(76.4 \%)$. Almost half $(49.3 \%)$ of the study subjects were illiterate. As per as the financial dependency status was considered, $59.5 \%$ of the elderly people were found to be fully dependent on their family members; $18.7 \%$ were partially dependent, and only $21.9 \%$ were found to be financially independent. The geriatric people were asked about their marital status. It revealed that more than half $(52.2 \%)$ were widowed, and $45.8 \%$ were living with spouse.

The main focus of the present study was to find out the association of psychological morbidities with different socio-demographic parameters. Analysis of the data revealed that $37.3 \%$ of the respondents scored 10 or more; so, they could be considered as psychological case. Further $33.3 \%$ respondents fell into caseness category. Only $29.4 \%$ scored less than five.

The prevalence of psychological morbidity according to age of the respondent was assessed. It was found that the prevalence increased significantly with an increase in age. Among people aged 70 years and above, $54.7 \%$ fell into case category and $30.5 \%$ fell into caseness category. On the other hand, the proportion of case and caseness were $31.9 \%$ and $34.2 \%$, respectively, among younger age group (60-69 years). This difference was statistically significant $(P<0.001)$.

Female respondents were found to be suffering from more psychological morbidities as compared to male. $42.9 \%$ of female in contrast to $30.1 \%$ male fell into case category. $40.3 \%$ male and $20.8 \%$ female fell into normal category. These differences were found to be statistically significant $(P<0.001)$.

The present study revealed that literacy is also an important factor in relation to psychological problems. $46.5 \%$ of illiterate respondents scored 10 or more (cases); on the other hand, this proportion is $28.4 \%$ among literate respondents. This difference was also highly significant $(P=0.001)$.

Financial dependency is closely associated with psychological morbidity. Analysis found out that $43.1 \%$ of geriatric persons, who were fully dependent on their family members for financial matter, fell into case category. This proportion was less than 30\% among people who were financially independent or only partially dependent on their family members. This difference was found to be highly significant $(P<0.001)$. 
Analysis was done to find out the association of marital status with the psychological morbidity. Only four persons were never married, and two persons were separated from their spouse. So, for the analysis to find association with marital status, geriatric people were divided into two groups-living with spouse and not living with spouse. The not living with spouse group is comprised of widowed, never married, and separated. It was found that prevalence of case and caseness was significantly low among people who were living with their spouse as compared to other group $(P<0.001)$.

Geriatric people were grouped into four categories according to four quartiles of per capita monthly income. It was revealed that prevalence of psychological morbidity was significantly decreased with increase in per capita monthly income $(P<0.001)$ [Table 1].

Multiple linear regression was done to further find out the independent factors, which can modify the total as well as domain-wise score of GHQ. The reference categories of different variables taken in the regression models were as below:

Age group: 60-69 years

Sex: Male

Literacy: Literate

Financial dependency: Independent

Marital status: Living with spouse

Per capita monthly income: Up to Rs. 750/-

The Multiple linear regression model for overall GHQ score indicates that age group, marital status, and per capita monthly income are significant predictor of the GHQ value. Age groups and marital status are the positive predictors of GHQ score as indicated by the positive sign of the regression coefficient (B). As lower age group is reference category, so positive sign indicates that with increase in age, the GHQ score is increased also, and this difference was found to be significant $(P=0.003,95 \%$ CI 0.725 to 3.541). Multiple linear model indicates that GHQ score was significantly high among people who were living with spouse as compared to the others ( $P=0.001,95 \%$ CI 1.014 to 3.930). The negative sign of regression coefficient (B) in case of per capita monthly income indicates that the score decreased gradually in successive groups after reference group; the reference group had highest score. Here, the reference group was most poor group; the successive groups were arranged according to increase in the per capita monthly income. So, with increase in the per capita monthly income, the GHQ score gradually decreased, and this difference was statistically significant $(P<0.001,95 \%$ CI -2.408 to -1.092$)$. In initial analysis by Chi-square test with individual variables, GHQ score was found to be significantly higher in female; but, in multiple linear regression model, sex is not found to be a significant predictor of GHQ score [Table 2].

Somatic symptom is the first domain in GHQ-28. Multiple linear regression model using somatic symptom as dependent variable indicates that age and marital status were significant positive predictors, and per capita monthly income was significant negative predictor of the somatic symptoms score. It revealed that with the

\begin{tabular}{|c|c|c|}
\hline Study variables & Category & No. (\%) \\
\hline \multirow[t]{2}{*}{ Age } & $60-69$ years & $307(76.4)$ \\
\hline & 70 years and above & $95(23.6)$ \\
\hline \multirow[t]{2}{*}{ Sex } & Male & $176(43.8)$ \\
\hline & Female & $226(56.2)$ \\
\hline \multirow[t]{2}{*}{ Literacy } & Illiterate & $198(49.3)$ \\
\hline & Literate & $204(50.7)$ \\
\hline \multirow[t]{3}{*}{ Financial dependency } & Independent & $88(21.9)$ \\
\hline & Partially dependent & $75(18.7)$ \\
\hline & Fully dependent & $239(59.5)$ \\
\hline \multirow[t]{4}{*}{ Marital status } & Living with spouse & $184(45.8)$ \\
\hline & Widowed & $210(52.2)$ \\
\hline & Never married & $6(1.5)$ \\
\hline & Separated & $2(0.5)$ \\
\hline \multirow{4}{*}{$\begin{array}{l}\text { Per capita monthly } \\
\text { income }\end{array}$} & Up to Rs. $750 /-$ & $112(27.9)$ \\
\hline & Rs. $751 /$ - to Rs.1200/- & $104(25.9)$ \\
\hline & Rs. $1201 /-$ to Rs. $3000 /-$ & $97(24.1)$ \\
\hline & More than Rs. 3000/- & $89(22.1)$ \\
\hline
\end{tabular}

Table 2: Distribution of study population according
to total GHQ score $(\boldsymbol{n}=\mathbf{4 0 2})$
\begin{tabular}{lc}
\hline Type according to GHQ scoring & No. $(\%)$ \\
\hline Normal (Less than 5$)$ & $118(29.4)$ \\
Caseness (5-9) & $134(33.3)$ \\
Case (10 or above) & $150(37.3)$ \\
Total & $402(100)$ \\
\hline
\end{tabular}

increase in age, GHQ score increased significantly $(P=0.001,95 \%$ CI 0.275 to 1.081$)$. The GHQ score was significantly lower among people living with spouse as compared to others $(P=0.033,95 \% \mathrm{CI}$ 0.036 to 0.871$)$. With the increase in the per capita monthly income, somatic symptoms score decreased significantly $(P<0.001,95 \%$ CI -0.589 to -0.212 ).

Multiple linear regression model using anxiety-insomnia score as dependent variable highlighted that anxiety-insomnia score was found to be significantly higher among older age group aged 70 years or more $(P=0.011,95 \%$ CI 0.127 to 0.954$)$, female sex $(P=0.028$, $95 \%$ CI 0.058 to 0.991$)$, illiterate people $(P=0.017,95 \%$ CI 0.099 to $1.020)$, and among lower income group $(P=0.001,95 \% \mathrm{CI}-0.531$ to -0.144$)$.

Another multiple linear regression model was formed using social dysfunction score as dependent variable. It revealed the fact that social dysfunction score was significantly predictable by literacy, financial dependency, marital status, and per capita monthly income. Literate people had significantly less score as compared to illiterate $(P=0.037,95 \%$ CI 0.036 to 1.119$)$; financially independent persons had significantly less score than dependent ones ( $P=0.043,95 \%$ CI 0.010 to 0.635 ); persons living with spouse scored significantly less than others $(P<0.001,95 \%$ CI 0.539 to 1.545$)$; poorer section of the community scored significantly higher $(P<0.001,95 \% \mathrm{CI}-0.673$ to -0.219$)$. 
Severe depression score was taken as dependent variable in last model of multiple linear regression. It was revealed that severe depression score was significantly higher in people aged 70 years and above $(P=0.025,95 \%$ CI 0.064 to 0.932$)$; among those not living with spouse $(P=0.007,95 \%$ CI 0.173 to 1.072$)$ and in lower income group $(P<0.001,95 \%$ CI having lower boundary -0.768 to upper boundary -0.362 ) [Tables 3 and 4].

\section{DISCUSSION}

Psychological problems in older age group are not uncommon in recent years. The prevalence of these problems varies from community to community due to the effect of different social factors affecting the mental health. With the increase in age, the ability to work is decreased gradually. At the same time, loneliness is increased also. At very high age, ultimately the importance of a person is decreased to other family members, leading to feeling of negligence by the family members. So, the mental health is seriously hampered. In the present study also, it was found that scores of all the domains of psychological health were significantly higher in people aged 70 years or more.
In the present social scenario of India, female persons are usually given less importance from the very beginning to the very end of life. Some literature review reveals the fact that depression is higher in older female as compared to male. ${ }^{[5]}$ The multiple linear regression model of the present study did not find any significant association of sex with total GHQ score, somatic symptoms score, social dysfunction score as well as severe depression score. But, female respondents scored significantly higher as per as anxiety-insomnia score was considered. The lack of social security of female, particularly of those not living with their spouse, may have effect in the anxiety domain.

Education helps a person to earn a good livelihood. Education gives an opportunity to get respect by the other members of the family and community and helps to have a good social position. In the present study, a large chunk of respondents were illiterate. It was revealed by analysis that anxiety-insomnia score and social dysfunction score were significantly higher in illiterate group.

In India, still the age of retirement is 60 years in most jobs. The persons working in private sectors usually do not get good

\begin{tabular}{|c|c|c|c|c|}
\hline \multirow[t]{2}{*}{ Study variables } & \multicolumn{3}{|c|}{ GHQ score } & \multirow[t]{2}{*}{ Total no. (\%) } \\
\hline & Normal no. (\%) & Caseness no. (\%) & Case no. (\%) & \\
\hline \multicolumn{5}{|l|}{ Age group } \\
\hline $60-69$ years & $104(33.9)$ & $105(34.2)$ & $98(31.9)$ & $307(100)$ \\
\hline 70 years and more & $14(14.7)$ & $29(30.5)$ & $52(54.7)$ & $95(100)$ \\
\hline \multicolumn{5}{|l|}{ Chi-square $=19.469$, d.f. $=2, P<0.001$} \\
\hline \multicolumn{5}{|l|}{ Sex } \\
\hline Male & $71(40.3)$ & $52(29.5)$ & $53(30.1)$ & $176(100)$ \\
\hline Female & $47(20.8)$ & $82(36.3)$ & $97(42.9)$ & $226(100)$ \\
\hline \multicolumn{5}{|l|}{ Chi-square $=18.573$, d.f. $=2, P<0.001$} \\
\hline \multicolumn{5}{|l|}{ Literacy } \\
\hline Illiterate & $48(24.2)$ & $58(29.3)$ & $92(46.5)$ & $198(100)$ \\
\hline Literate & $70(34.3)$ & $76(37.3)$ & $58(28.4)$ & $204(100)$ \\
\hline \multicolumn{5}{|l|}{ Chi-square $=14.140$, d.f. $=2, P=0.001$} \\
\hline \multicolumn{5}{|l|}{ Financial dependency } \\
\hline Independent & $43(48.7)$ & $19(21.6)$ & $26(29.5)$ & $88(100)$ \\
\hline Partially dependent & $27(36.0)$ & $27(36.0)$ & $21(28.0)$ & $75(100)$ \\
\hline Fully dependent & $48(20.1)$ & $88(36.4)$ & $103(43.1)$ & $239(100)$ \\
\hline \multicolumn{5}{|l|}{ Chi-square $=29.517$, d.f. $=4, P<0.001$} \\
\hline \multicolumn{5}{|l|}{ Marital status } \\
\hline Living with spouse & $80(43.5)$ & $53(20.8)$ & $51(27.7)$ & $184(100)$ \\
\hline Not living with spouse & $38(17.4)$ & $81(37.2)$ & $99(45.4)$ & $218(100)$ \\
\hline \multicolumn{5}{|l|}{ Chi-square $=33.524$, d.f. $=2, P<0.001$} \\
\hline \multicolumn{5}{|l|}{ Per capita monthly income } \\
\hline Up to Rs. $750 /-$ & $20(17.9)$ & $34(30.4)$ & $58(51.8)$ & $112(100)$ \\
\hline Rs. $751 /-$ to Rs. $1200 /-$ & $27(26.0)$ & $33(31.7)$ & $44(42.3)$ & $104(100)$ \\
\hline Rs. $1201 /-$ to Rs. $3000 /-$ & $33(34.0)$ & $34(35.1)$ & $30(30.9)$ & $97(100)$ \\
\hline More than Rs. 3000/- & $38(42.7)$ & $33(37.1)$ & $18(20.2)$ & $89(100)$ \\
\hline Chi-square $=27.414$, d.f. $=6, P<0.001$ & & & & \\
\hline
\end{tabular}




\begin{tabular}{|c|c|c|c|c|c|}
\hline \multirow[t]{2}{*}{ Models } & \multicolumn{2}{|c|}{ Un-standardized coefficient } & \multirow[t]{2}{*}{$P$ value } & \multicolumn{2}{|c|}{$95 \%$ Confidence interval for $(B)$} \\
\hline & $\begin{array}{l}\text { Regression } \\
\text { coefficient (B) }\end{array}$ & $\begin{array}{l}\text { Standard } \\
\text { error of (B) }\end{array}$ & & $\begin{array}{l}\text { Lower } \\
\text { boundary }\end{array}$ & $\begin{array}{c}\text { Upper } \\
\text { boundary }\end{array}$ \\
\hline \multicolumn{6}{|l|}{ Total GHQ score } \\
\hline Constant & 2.869 & 2.048 & 0.162 & -1.158 & 6.896 \\
\hline Age group & 2.133 & 0.716 & 0.003 & 0.725 & 3.541 \\
\hline Sex & 0.516 & 0.808 & 0.523 & -1.072 & 2.104 \\
\hline Literacy & 1.358 & 0.798 & 0.090 & -0.210 & 2.927 \\
\hline Financial dependency & 0.507 & 0.461 & 0.272 & -0.399 & 1.413 \\
\hline Marital status & 2.472 & 0.742 & 0.001 & 1.014 & 3.930 \\
\hline Per capita monthly income & -1.750 & 0.335 & $<0.001$ & -2.048 & -1.092 \\
\hline \multicolumn{6}{|l|}{ Somatic symptoms score } \\
\hline Constant & 0.513 & 0.587 & 0.383 & -0.641 & 1.667 \\
\hline Age group & 0.678 & 0.205 & 0.001 & 0.275 & 1.081 \\
\hline Sex & 0.225 & 0.231 & 0.333 & -0.230 & 0.680 \\
\hline Literacy & 0.345 & 0.229 & 0.132 & -0.105 & 0.794 \\
\hline Financial dependency & 0.211 & 0.132 & 0.111 & -0.049 & 0.470 \\
\hline Marital status & 0.454 & 0.213 & 0.033 & 0.036 & 0.871 \\
\hline Per capita monthly income & -0.401 & 0.096 & $<0.001$ & -0.589 & -0.212 \\
\hline \multicolumn{6}{|l|}{ Anxiety-insomnia score } \\
\hline Constant & 0.510 & 0.602 & 0.397 & -0.673 & 1.694 \\
\hline Age group & 0.541 & 0.210 & 0.011 & 0.127 & 0.954 \\
\hline Sex & 0.525 & 0.237 & 0.028 & 0.058 & 0.991 \\
\hline Literacy & 0.559 & 0.234 & 0.017 & 0.099 & 1.020 \\
\hline Financial dependency & -0.017 & 0.135 & 0.902 & -0.283 & 0.249 \\
\hline Marital status & 0.354 & 0.218 & 0.105 & -0.075 & 0.782 \\
\hline Per capita monthly income & -0.338 & 0.098 & 0.001 & -0.531 & -0.144 \\
\hline \multicolumn{6}{|l|}{ Social dysfunction score } \\
\hline Constant & 0.423 & 0.707 & 0.550 & -0.967 & 1.812 \\
\hline Age group & 0.416 & 0.247 & 0.093 & -0.069 & 0.902 \\
\hline Sex & -0.273 & 0.279 & 0.328 & -0.821 & 0.275 \\
\hline Literacy & 0.578 & 0.275 & 0.037 & 0.036 & 1.119 \\
\hline Financial dependency & 0.322 & 0.159 & 0.043 & 0.010 & 0.635 \\
\hline Marital status & 1.042 & 0.256 & $<0.001$ & 0.539 & 1.595 \\
\hline Per capita monthly income & -0.446 & 0.116 & $<0.001$ & -0.673 & -0.219 \\
\hline \multicolumn{6}{|l|}{ Severe depression score } \\
\hline Constant & 1.423 & 0.631 & 0.025 & 0.182 & 2.665 \\
\hline Age group & 0.498 & 0.221 & 0.025 & 0.064 & 0.932 \\
\hline Sex & 0.039 & 0.249 & 0.874 & -0.450 & 0.529 \\
\hline Literacy & -0.124 & 0.246 & 0.616 & -0.607 & 0.360 \\
\hline Financial dependency & -0.009 & 0.142 & 0.948 & -0.288 & 0.270 \\
\hline Marital status & 0.622 & 0.229 & 0.007 & 0.173 & 1.072 \\
\hline Per capita monthly income & -0.565 & 0.103 & $<0.001$ & -0.768 & -0.362 \\
\hline
\end{tabular}

rehabilitation scheme after retirement as far as financial matter is considered. So, a large proportion of them are financially dependent on the other members of the family. Persons working in agriculture or in business also sometimes feel difficulty in working in the old age due to lack of physical efficiency. So, they also become partially or fully dependent on family members. This dependency often leads to psychological problems. Studies highlight that financial dependency has a strong relation with mental and physical health of geriatric people. ${ }^{[6,7]}$ Analysis of the data of present study highlights that social dysfunction score was significantly higher among those who were financially dependent on their family members.
The lonely elderly people often get no one to share his/her feelings except the spouse. At this age, the person who takes care of him/ her most is the spouse in most of the cases. The widowed elderly people are lonelier; often no one is there to hear his/her feelings; to take care of him/her. So, the psychological health is badly affected. In the present study also, it was found that total GHQ score, somatic symptoms score, and severe depression score were significantly higher in widowed, separated, and never married group (not living with spouse) as compared to those living with spouse.

Sufficient income gives social security. In this study, it was found that higher income group scored significantly low as compared to 
low income category as far as total GHQ score as well as scores of all the domains was considered.

\section{REFERENCES}

1. Elango S. A study of Health and Health related Social Problems in the Geriatric Population in a Rural Area of Tamilnadu. Indian J Public Health 1998;42:7-8.

2. Mobbs C. The Merck Manual of Geriatrics, Section 1, Chapter 1, Biology of Aging. Available from: http://www.merck.com/pubs/mm_geriatrics/ sec1/ch1.htm, [last accessed on 2001 Apr 12].

3. Hafez G, Bagchi K, Mahaini R. Caring for the elderly: A Report on the status of Care for the Elderly in the Eastern Mediterranean Region. East Mediter Health J 2000;6:636-51.

4. Goldberg SE, Whittamore KH, Harwood RH, Bradshaw LE, Gladman JR, Jones RG, et al. Medical Crises in Older People Study Group. The prevalence of mental health problems among older adults admitted as an emergency to a general hospital. Age Ageing 2012;41:80-6.
5. Ried LD, Gerhard T, Tueth MJ. Depressive symptoms and physical functioning: Are older females and males different?. J Behav Health 2012;1:16-27.

6. Uwakwe R, Ibeh CC, Modebe AI, Bo E, Ezeama N, Njelita I, et al. The epidemiology of dependence in older people in Nigeria: Prevalence, determinants, informal care, and health service utilization. A 10/66 dementia research group cross-sectional survey. J Am Geriatr Soc 2009;57:1620-7.

7. Acosta D, Rottbeck R, Rodríguez G, Ferri CP, Prince MJ. The epidemiology of dependency among urban-dwelling older people in the Dominican Republic; a cross-sectional survey. BMC Public Health 2008;8:285-95.

How to cite this article: Datta PP, Gangopadhyay N, Sengupta B. Association of psychological morbidity with socio-demographic characteristics among elderly: A cross-sectional study from Eastern India. Int J Med Public Health 2013;3:94-9.

Source of Support: Nil, Conflict of Interest: None declared. 